\title{
NONLINEAR EFFECTS OF FEMALE MATE CHOICE IN WILD THREESPINE STICKLEBACKS
}

\author{
Jonatan Blais, ${ }^{1,2}$ Ciro Rico, ${ }^{3,4}$ And Louis Bernatchez ${ }^{1,5}$ \\ ${ }^{1}$ Département de biologie, Québec-Océan, Université Laval, Ste-Foy, Québec GIK 7P4, Canada \\ ${ }^{2}$ E-mail: Jonatan.Blais.1@ulaval.ca \\ ${ }^{3}$ Estación Biológica de Doñana, Consejo Superior de Investigaciones Cientificas, Avenida de Maria Luisa s/n Pabellón del Perú, \\ Apartado de correos 1050, 41013, Sevilla, Spain \\ 4E-mail:Ciro@ebd.csic.es \\ ${ }^{5}$ E-mail: Louis.Bernatchez@bio.ulaval.ca
}

\begin{abstract}
Sexual selection by mate choice represents a very important selective pressure in many animal species and might have evolutionary impacts beyond exaggeration of secondary sexual traits. Describing the shape and strength of the relationships linking mating success and nonsexual traits in natural conditions represents a challenging step in our understanding of adaptive evolution. We studied the effect of behavioral (nest site choice), immunological (trematode level of infection), genetic diversity (measured by mean $d^{2}$ ) and morphological (standard length and pectoral fin size) traits on male mating success in a natural population of threespine sticklebacks Gasterosteaus aculeatus. Male mating success was measured by microsatellite genotyping of embryos used to infer female genotypes. First, we analyzed all territorial males (full analysis) but also considered independently only males with a nonzero mating success (reduced analysis) because some of the males with no eggs could have been part of a later breeding cycle. Multiple linear regressions identified a significant negative effect of parasite load in the full analysis, whereas no linear effect was found in the reduced analysis. The quadratic analyses revealed that nest location and parasite load were significantly related to mating success by positive (concave selection) and negative (convex selection) quadratic coefficients respectively, resulting in a saddle-shaped fitness surface. Moreover, there were significant interactions between nest location, mean $d^{2}$ and parasite load in the reduced analysis. The subsequent canonical rotation of the matrix of quadratic and cross-product terms identified two major axes of the response surface: a vector representing mostly nest site choice and a vector representing parasite load. These results imply that there exists more than one way for a male threespine stickleback to maximize its mating success and that such nonlinear relationships between male mating success induced by female mate choice and male characteristics might have been overlooked in many studies.
\end{abstract}

Key words._Gasterosteus aculeatus, immunocompetence, mate choice, mean $d^{2}$, parasite load, reproductive success, sexual selection.

The evolutionary implications of sexual selection beyond exaggeration of male ornaments and reproductive isolation depends on its direct and indirect impact on other traits (Hunt et al. 2004), which in turn depends on the shape and strength of the relationships linking mating success to these traits. Exactly what traits contribute to mating success or are affected by it, and especially what is the nature of their relationships with this component of fitness, have been notoriously difficult to determine in the wild (e.g., Saether et al. 2000; Pryke et al. 2001; Webberley et al. 2002). Empirical investigations of mate choice in natural conditions face important difficulties, including the challenge of accurately documenting mating success, the choice of traits potentially involved or affected by the mate choice process, and the statistical analyses of often complex multivariate datasets. One such statistical issue concerns the detection and measurement of nonlinear and correlational (interraction effects) selection (Lande and Arnold 1983; Blows and Brooks 2003).

Correlational selection is of particular interest in the context of mate choice because mate preferences are thought to affect several characteristics simultaneously (Johnstone 1995; Doucet and Montgomerie 2003; Blanckenhorn et al. 2004) and there is ample evidence that functional interactions are important in determining organismal performance (Kingsoler et al. 2001). Nevertheless, little is known about the effect of correlational selection in the wild (Kingsolver 2001). In this context, the analysis of selection based on the general multiple regression framework first proposed by Lande and Arnold (1983) has become the paradigm of fitness-determinant studies such as mating success analyses. In principle, it allows for the detection of nonlinear and correlational selection. Yet, this method is not without constraints and limitations.

First, this approach has limited power for sample sizes below one hundred (Hersch and Phillips 2004), restricting its ability to reveal weak effects and thus potentially leading to publication bias and perhaps a distorted view of the effect of selection in the wild (Hersch and Phillips 2004). Second, the nature of regression analysis also requires relatively large sample sizes to analyze second-order (nonlinear selection) and interraction effects on multiple traits. Large sample sizes are notoriously difficult to obtain in the wild for many animal systems, particularly vertebrates. Finally, rigorous multivariate regression analyses of nonlinear selection should include the canonical rotation of the response surface to accurately measure the strength of nonlinear effects. For instance, Blows and Brooks (2003) showed how nonlinear selection can be underestimated if the canonical rotation is omitted. Unfortunately, this step is usually ignored in most studies.

Despite the problems associated with the accurate measurement of mating success in natural conditions and the subsequent analysis of selection and fitness determinants, such studies are crucial for our understanding of sexual selection and the evolution of mate preferences. Sexual be- 

haviors are often the most sensitive to captivity conditions and so laboratory studies of mate choice will always suffer from the uncertainty of whether their findings are relevant to natural systems (Candolin and Voigt 2001). Moreover, there is a need for further documentations of the relative strength of linear and nonlinear sexual selection, particularly to determine the impact it may have on speciation (Arnegard and Kondrashov 2004; Kirkpatric and Nuismer 2004). In addition, stabilizing selection is central to many aspects of the evolutionary theory (adaptive landscape and phenotype optimization, maintenance of genetic variance and stability of the G-matrix); yet, most studies seem to detect significant directional selection much more often (Kingsolver et al. 2001). A possible cause for this apparent prevalence of directional selection is researcher bias for systems or traits where directional selection is likely and expected (Kingsolver et al. 2001).

Here, we documented the mating success of male threespine stickleback (Gasterosteus aculeatus) in coastal tide pools of the St. Lawrence River estuary to explore the possibility of studying nonlinear and correlational selection induced by mate choice in natural conditions by combining Lande and Arnold's (1983) multiple regression framework and the canonical analysis of $y$. The Gasterosteidae is a small teleost family comprising eight species, all polygynandrous with paternal care. It represents one of six families of the order Gasterosteiformes, whose sister taxa is the Syngnathiformes, including the sex-role-reversed pipefishes and sea horses. During the breeding season, males compete to establish a territory within a colony. They build an elaborate tunnelshaped nest made of vegetation adhered with a secretion from the kidneys and then court females through a ritualized courtship display (Whoriskey and FitzGerald 1985a; Mori 1994). Males provide exclusive parental care whereby they guard the nest against predators, oxygenate eggs by fanning using their pectoral fins, and remove unviable eggs (Bell and Foster 1994). The cost of choice for females is likely to be low since males typically nest in high density and display intensively.

Several traits have been suggested to be involved in male G. aculeatus mating success for the possible benefits they provide to the female. Nest location is thought to influence the predation risk affecting both the embryos and the guarding male (FitzGerald 1983; Mori 1994; Kraak et al. 1999a). Based on findings of a sexual dimorphism where males had larger pectoral fins then females and considering that pectoral fins are used in parental care, several authors suggested that this trait could also be involved in mate choice (Brønseth and Folstad 1997; Bakker and Mundwiler 1999; Künzler and Bakker 2000). Larger body size has been associated with increased vigor in parental care, including in threespine stickleback (Côté and Hunte 1989; Wiegmann and Baylis 1995; Kraak et al. 1999b), and there are also reports of size assortative mating in this species (Kraak and Bakker 1998; McKinnon et al. 2004). Hence, this trait might be important in determining mating success. Finally, traits such as level of parasite infection and level of genetic diversity have also been hypothesized to be affected by sexual selection (e.g., Hamilton and Zuk 1982; David 1998; Neff 2004). However, recent theoretical results suggested that the shape of the relationship between male parasite load and level of sexual attractiveness is undetermined by theory and must be assessed empirically (Getty 2002). Therefore, additional data are necessary to fully understand the link between this factor and mating success in the wild.

In this context, our specific objectives were to explore the shape and strength of the relationships linking mating success due to nonrandom female mate choice and five traits previously suggested to be affected by mate choice: male body and pectoral fin size, nest location, parasite load, and withinindividual genetic diversity, in completely natural conditions. Using parentage analysis based on multilocus genotype information, we examined the relationship between male mating success and this combination of different categories of traits to identify those worthy of future experimental investigations. Since sample size sets an upper limit to the number of traits that can be included in the analysis, we did not consider secondary sexual traits that are already known to be under directional selection in general (Pomiankowski and Møller 1995) and in this species in particular (Milinski and Bakker 1990; Bakker and Milinski 1993; Rowland 1995). Thus, we focused on characteristics that are potentially indirectly affected by open-ended female preference for such signal traits and for which the effects of mate choice might not be predicted as necessarily directional. We also applied the correct response surface methodology by performing the canonical rotation of the matrix of quadratic and cross-product terms to obtain accurate estimates of nonlinear selection.

\section{Materials And Methods}

\section{Study Site and Field Sampling}

Sticklebacks were collected from an anadromous population of the St. Lawrence River estuary (Quebec, Canada). One- and two-year-old individuals migrate each spring (May and June) from this estuary to reproduce in coastal tide pools of the Isle Verte National Wildlife Area. The most prevalent parasites in this population are digenic trematodes causing blackspot disease (FitzGerald et al. 1994). Field sampling was carried out at the beginning of the breeding season in May, following one of the first high spring tides flooding the area. Because of the short breeding season, most males of this population are able to complete only one breeding cycle per breeding season (Lachance and FitzGerald 1992 and references therein).

A total of 139 nests, of which 48 (35\%) contained eggs, were located. Distances among nests within the pool were measured to the nearest centimeter and mapped. Following the end of the egg-collecting phase, which typically last between two to six days (Jamieson et al. 1992; Kraak et al. 1999a), territorial males were captured with a hand net. Sampling was done 15 days after flooding, as previous data showed that the egg-collecting phase of the male breeding cycle, which starts just after the flood, is over by then (Fitzgerald 1983). Following a guardian male capture, all eggs found in its nest were also immediately collected. After all territorial males were caught, females and nonterritorial males were captured by seining, ensuring that most (if not all) fish present were collected. All fish and eggs were immediately put on dry ice and then kept at $-80^{\circ} \mathrm{C}$. A total of 605 adult fish were captured, including 325 (54\%) females 
TABLE 1. Microsatellite loci statistics and polymerase chain reaction amplifying conditions. Min and Max, minimum and maximum allele size in base pairs; A, number of alleles; $\left[\mathrm{A}_{0}\right]$, estimated null allele frequency; $\mathrm{H}_{0}$, obser ved heterozygosity; $\mathrm{H}_{\mathrm{e}}$, expected heterozygosity.

\begin{tabular}{|c|c|c|c|c|c|c|c|c|}
\hline Locus & Min (bp) & Max (bp) & A & {$\left[\mathrm{A}_{0}\right]$} & $\mathrm{H}_{\mathrm{o}}$ & $\mathrm{H}_{\mathrm{e}}$ & $\begin{array}{l}\text { Exclusion } \\
\text { probability }{ }^{1}\end{array}$ & $\begin{array}{c}\text { Annealing } \\
\mathrm{T}\left({ }^{\circ} \mathrm{C}\right)^{2}\end{array}$ \\
\hline$\overline{\mathrm{Gac}} \mu 4$ & 108 & 138 & 14 & -0.002 & 0.85 & 0.85 & 0.524 & 61 \\
\hline Gacu10 & 180 & 298 & 54 & -0.002 & 0.97 & 0.97 & 0.893 & 62 \\
\hline CIER51 & 168 & 314 & 61 & 0.004 & 0.91 & 0.91 & 0.722 & 60 \\
\hline CIER62 & 100 & 176 & 33 & 0.022 & 0.90 & 0.95 & 0.802 & 60 \\
\hline Overall & & & & & & & 0.999 & \\
\hline
\end{tabular}

\footnotetext{
1 The average exclusion probability represents the probability of excluding an unrelated individual as the parent of an offspring when neither of the two parents of this offspring are known.

2 The annealing temperature refers to the final temperature preceded by a touchdown of two cycles at each temperature starting $5^{\circ} \mathrm{C}$ above and separated by steps of $1^{\circ} \mathrm{C}$.
}

and 280 males (territorials and nonterritorial males). Thus, the resulting adult sex ratio was 1.161:1 (slightly female biased).

\section{Mating Success Estimation}

Female threespine stickleback lay their eggs as a clutch, within which eggs stick together during the first days of incubation. Therefore, eggs from each nest were first separated by clutch. To obtain accurate estimates of mating success, simply counting the number of eggs or clutches in a male's nest is not sufficient because females can vary greatly in clutch size (Bell and Foster 1994), and the manual separation of eggs into distinct clutches is difficult and prone to error as these are fragile and can easily break or fuse. Moreover, clutch and nest take-over is known to occur in threespine stickleback (Rico et al. 1992; Jones et al. 1998). Thus, the correlation between the number of eggs or clutches in a nest and the number of females attracted by the male is noisy. Because a difference of only plus or minus one female can change the mating success rank order of males and therefore compromise the validity of this type of count data regression analysis, for each clutch $10 \%$ of the egg mass was randomly sampled for parentage assignment by multilocus microsatellite genotyping. Ten percent is considered conservative to detect all parents of an egg mass of the sizes encountered (50300 eggs; DeWoody et al. 2000).

Prior to DNA extraction, all eggs were checked with a stereoscope to determine their developmental stage to ensure that the analysis would only compare males in similar phase of their breeding cycle (Swarup 1958). DNA extractions were performed using a Bilatest Genomic DNA kit magnetic beads extraction method (Bilatec, AG, Inc. Mannheim, Germany). Five dinucleotide repeat microsatellite loci were amplified using polymerase chain reaction (PCR) and typed for each egg and adult individual: CIER11, CIER51, and CIER62 (Rico et al. 1993), Gach4 and Gac $\mu 10$ (Taylor 1998; see Table 1). Four of these loci (CIER11, CIER51, CIER62, and Gac 410 ) have been mapped to four different linkage groups of the 21 chromosomes of the threespine stickleback (Peichel et al. 2001). Exclusion probabilities, null alleles frequencies, and departure from Hardy-Weinberg equilibrium were calculated using CERVUS 2.0 (Marshall et al. 1998). Fluorescently labeled fragments were visualized with an ABI Prism 377 sequencer (Applied Biosystems, Inc., Foster City, CA), and allele sizes were scored using ABI Prism Genescan and Genotyper (Applied Biosystems).

Overall, 1197 eggs from 44 nests containing eggs were genotyped as follow: $73 \%$ could be genotyped at the five microsatellite loci, $18 \%$ at four loci, and the remaining $9 \%$ at between one and three loci. Missing genotypes were due to either amplification problems likely caused by reduced extraction yield and DNA quality or allele size scoring uncertainty caused by stutter bands. However, given the extremely high variability of the loci used, the exclusion probabilities of the parentage assignment based on fewer than five loci were never less than $89.3 \%$ (see Table 1, probability value of Gach10). All guardian males' multilocus genotypes were also scored. Parentage was then assigned manually without the use of an assignment software to efficiently make use of the information provided by the known suspected parent (the guardian male) combined with the full-sib and half-sib information provided by the clutch structure, which facilitated the identification of parental relationships compared with maximum likelihood or other statistical approaches.

Male mating success was determined by the number of different female genotypes, deduced by allele subtraction, found in its nest. A given guardian male was excluded as putative father if no allele of a given offspring matched those present in that male at one or more loci. Exclusion of the guardian male as the father of part of the eggs of a given clutch was interpreted as a sneaking event, and no correction was made on its mating success value (Rico et al. 1992). If the guardian male was excluded for all the eggs of a clutch or for all the eggs of its nest, this was interpreted as a takeover (stealing of a clutch of eggs or of a nest; Rico et al. 1992). In this case, mating success was awarded to the genetic father, if found in the genotype database.

Despite the precision in male mating success determination provided by the genetic data, egg cannibalism by guardian males (Fitzgerald and Van-Havre 1987) could lead to underestimation of mating success for some cannibal males. We recorded the occurence of egg cannibalism among territorial males by examining stomach and gut contents for the presence of eggs to provide an assessment of the relative importance of the uncertainty this behavior could introduce.

\section{Genetic and Phenotypic Traits}

Because the majority ( $>72 \%$ ) of genotyped adult fish were heterozygotes at all scored loci, the usefulness of standard 
multilocus heterozygosity (MLH) estimate was limited for documenting the relationship between level of inbreeding and mating success. In such circumstances, genetic diversity may be better estimated by taking into account the extent of allelic divergence in terms of mutational events (Goldstein et al. 1995; Tsitrone et al. 2001) such as the $d^{2}$ parameter. Moreover, this index outperforms heterozygosity in detecting deep inbreeding and high levels of genomic divergence when the mutation rate and population sizes are high (Tsitrone et al. 2001; Neff 2004), two conditions likely to apply to the present case given the large observed number of alleles and population sizes of fish species such as anadromous G. aculeatus. This genetic index was also shown to be involved in mate choice in the bluegill sunfish (Lepomis macrochirus; Neff 2004) and the black grouse (Tetrao tetrix; Höglund et al. 2002). In addition, correlations between mean $d^{2}$ and fitness-related traits have previously been reported in various vertebrates (Coltman et al. 1998; Coulson et al. 1998; Marshall and Spalton 2000; Rossiter et al. 2001), including fish (Health et al. 2002). Comparison of paired effect sizes reported from studies having used both MLH and mean $d^{2}$ revealed no significant differences between the two indices (Coltman and Slate 2003).

In addition to mean $d^{2}$, measurements were obtained on four additional traits. Standard length (SL) and pectoral fin size were measured to the nearest $0.1 \mathrm{~mm}$ (Bakker and Mundwiler 1999). The number of digenic trematode metacercaria (from the genera Uvulifer, Crassiphilia, Ornithodiplostomum, and Postodiplostomum) causing blackspot disease was counted on each fish and used as a measure for parasite load (Fig. 1). Each blackspot was assumed to represent infection by one cercaria (FitzGerald et al. 1994). This disease negatively affects growth and survival in many fishes (e.g., Lemly and Esch 1984), and susceptibility to infection by digenic trematodes in threespine sticklebacks has been shown to be influenced by MHC allelic composition (Wegner et al. 2003). Given their prevalence in the study system and their known virulence, these parasites are therefore likely to represent an important selection pressure. Finally, the shortest distance from the nest to the shore of the pool ("distance to shore" or "nest site choice" hereafter) was measured to the nearest $5 \mathrm{~cm}$ and used as a territorial measure, as it is highly positively correlated to water depth and highly negatively correlated with vegetation cover (J. Blais, unpubl. data). These two aspects of territorial quality are potentially important for the protection they offer against conspecific and heterospecific predators such as birds (e.g., great blue heron Ardea herodias). Birds represent the most common heterospecific predators in this area and can remove up to $30 \%$ of the sticklebacks present in the system (Whoriskey and Fitzgerald 1985b). Distance to shore is thus likely to include substantial information about territorial quality and can be more objectively quantify than the two other characteristics separately. Mean $d^{2}$ and parasite load were $\log _{10}$ transformed, and distance to shore was square-root transformed prior to analysis. All variables were standardized to mean zero and variance one.

\section{Regression Analyses and Surface Visualization}

Because mating success counts typically follow a Poisson distribution (Schluter and Nychka 1994), all regressions were performed under a log-linear model for response with Poisson distribution (SAS PROC GENMOD, SAS Institute, Inc., Cary, NC). The relationships between mating success and the measured traits was first assessed by a purely linear multiple regression (Lande and Arnold 1983). The y matrix of nonlinear and cross-product terms was then obtained from a quadratic regression (Lande and Arnold 1983). The square-root of Pearson's chi-square divided by the degrees of freedom was used as scale parameter (McCullagh and Nelder 1989). The level of significance of the estimates were obtained using log-likelihood ratios tested against a chi-square distribution under a Type III sum of squares hypothesis.

Following the suggestion from Phillips and Arnold (1989) and emphasized by Blows and Brooks (2003), we performed the canonical rotation of the ç matrix to analyze nonlinear relationships along the major axes of the response surface using SAS PROC IML. The eigenanalysis of the ç matrix (which has the quadratic coefficients of the quadratic regression on its diagonal and the interaction coefficients off the diagonal) returns the eigenvalues and the eigenvectors $\left(m_{i}\right)$ of the $A$ canonical form comprising the $\mathbf{M}$ matrix and representing the major axes of the surface (Phillips and Arnold 1989), therefore removing the effect of the cross-product terms. The eigenvectors represent new combinations of the independent variables and are used to replace the original independent variables in the surface quadratic equation. The quadratic analysis is thus carried out again with these new variables (the eigenvectors) and the new quadratic coefficients correspond to the eigenvalues of $y$ (Blows and Brooks 2003).

The surfaces were visualized by thin-plate splines and by the best quadratic approximation using S-PLUS (Insightful Corp., Seattle, WA), along the major axes identified by the canonical rotation of $y$. In contrast to the best quadratic approximation of the surface, thin-plate splines make no assumption about the surface's shape and therefore allows local feature of the surface to be determined (Blows et al. 2003). The same number of grid division $(21 \times 21)$ was chosen for all surfaces to facilitate comparison. Bayesian 95\% confidence intervals were generated by S-PLUS using the upper and lower limits of the $95 \%$ confidence interval calculated for the mean of the predicted value for each observed value by the SAS PROC GENMOD, to place 95\% upper and lower bounds on the thin-plate spline surface's shape. Such a confidence interval does not represent the probability of observing a point at any specific value of the traits, but rather the probability of the true surface shape to lie between these higher and lower bounds (Blows et al. 2003).

\section{RESULTS}

\section{Mating Success and Parentage Assignment}

A total of 1185 eggs among the 1197 examined for developmental stages were between developmental stages 21 and 24 (130 to $168 \mathrm{~h}$ after fertilization). These represent the last four stages before hatching (Swarup 1958). The other 12 fries belonged to three clutches found in three different nests and were at stage 26 (approximately $192 \mathrm{~h}$ after fertilization). This corresponds to the first stage after hatching, but still several days before the fry leave the nest (Bell and Foster 


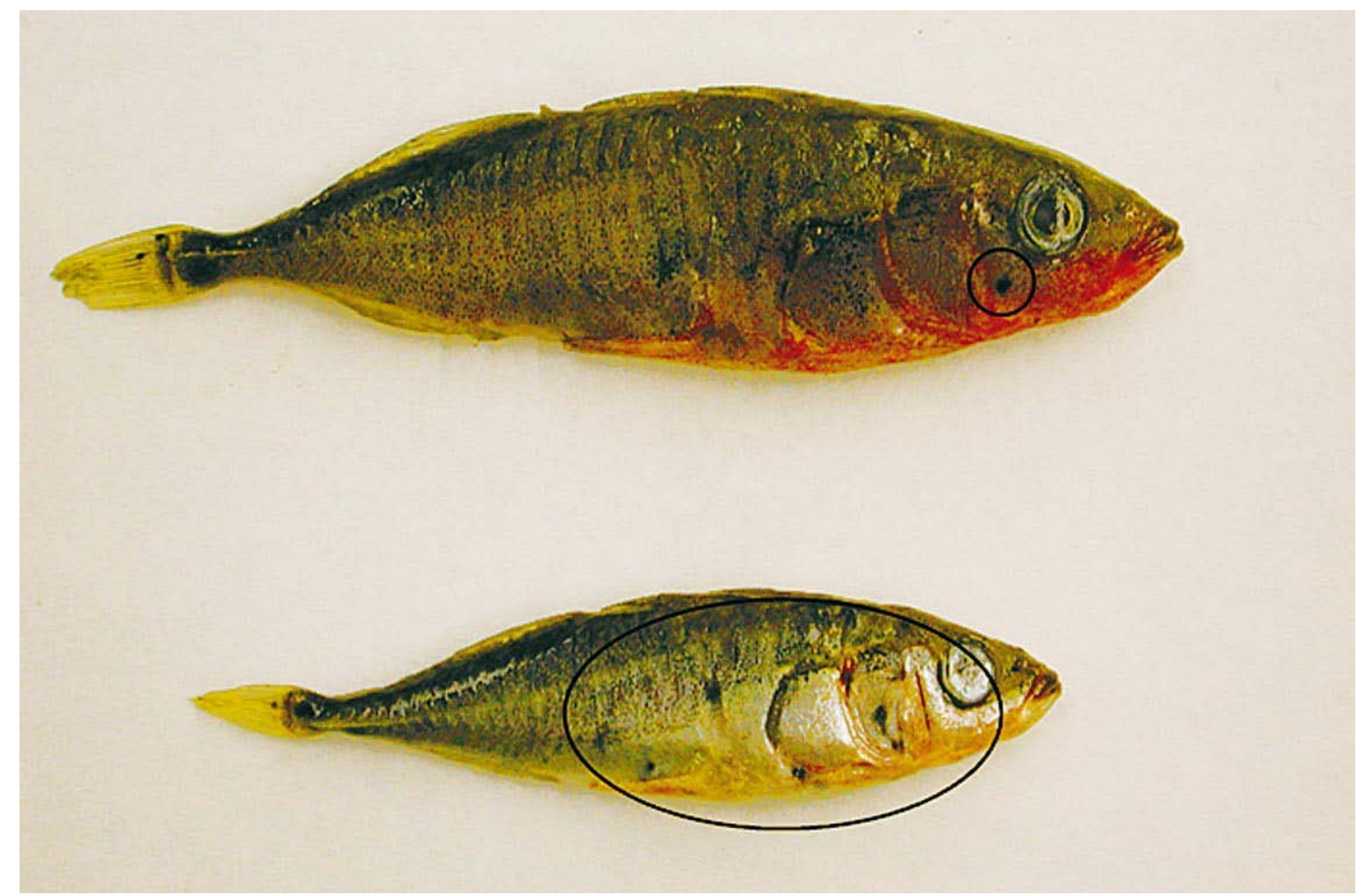

FIG. 1. Examples of melanophore-filled capsules of connective tissue (blackspots) produced in response to infection by free-swimming trematode cercaria on the threespine stickleback, Gasterosteus aculeatus. The individual on top shows signs of infection by one cercaria (circled), while the individual below had 11 of these parasites on its right side (circled). Observed parasite load among all fish examined ranged from zero to 100 per individual.

1994). This indicates that all territorial males with eggs used in the analysis were part of a same and highly synchronized breeding cycle, and that eggs were collected during the parental phase that follow the termination of the egg-collecting phase (Bell and Foster 1994). Therefore, it is very unlikely that the males used in the analysis would have acquired more eggs during this cycle, and that enough fry had already left the nests to significantly affect male mating success values. Hence, the data represent an accurate snapshot of the outcome of female mate choice among this particular set of males.

In addition, we found a relatively low occurrence of egg cannibalism among territorial males, with $37 \%$ of them showing evidence of between one and 40 cannibalized eggs in their digestive tract. This suggests that none of these males had recently eaten more than one clutch of eggs. These eggs could have either come from their own nest, leading to a possible understimation of these males mating success if the eggs eaten were not from a previously stolen clutch, or from the nests of neighboring rivals, in which case it would have no impact on their own estimated mating success but possibly on the mating success of the neighbor (FitzGerald and VanHavre 1987). Overall, the possible mating success underestimation of these cannibal males appears unlikely to significantly affect the results of the analysis, although it might contribute to an increase in the noise of the data.

The mean number of alleles per locus was 40 (range: 1461), yielding a combined exclusion probability greater than 0.999 , and a single locus exclusion probability range of 0.524 to 0.893 (Table 1). No significant departure from HardyWeinberg equilibrium or null alleles were detected for any of the loci. Genotype analysis led to limited exclusion of the guardian male as the genetic father of the eggs sampled from its nest. Indeed, extranest paternity was detected in nine of 44 nests (20\%), with an average of $15 \%$ (range: $2-40 \%$ ) of eggs in each of these nine nests fertilized by a sneaker, which therefore represented only $3 \%$ of all the eggs genotyped. The occurrence of clutch or nest take-over was detected in four nests (9\% of all nests), and represented $7 \%$ of all eggs. In these cases, no mating success was awarded to the guardian male captured at this nest. The genetic father for one of the nest take-over could be identified in the genotype database and the mating success of this nest was awarded to this male, which had been identified as nonterritorial upon capture. In summary, evidence of either extranest paternity or take-over was found in $30 \%$ of the nests, a value comparable to those reported in previous stickleback studies (Rico et al. 1992; Jones et al. 1998). Male mating success ranged from zero to five females attracted per nest (mean ! SE $=0.942$ ! 0.141). The phenotypes of the males for the studied traits and their mating success are given in Appendix 1 (available online at http://dx.doi.org/10.1554/04-189.1.s1).

\section{Phenotypic Traits}

We tested for the sexual dimorphism in pectoral fin size reported in two previous studies on European stickleback populations (Brønseth and Folstad 1997; Bakker and Mundwiler 1999) using an ANCOVA, with pectoral fin size as dependent variable, sex, and SL as covariate (Fig. 2). Both SL and sex had significant effects (sex: $F=14.532, P<$ 


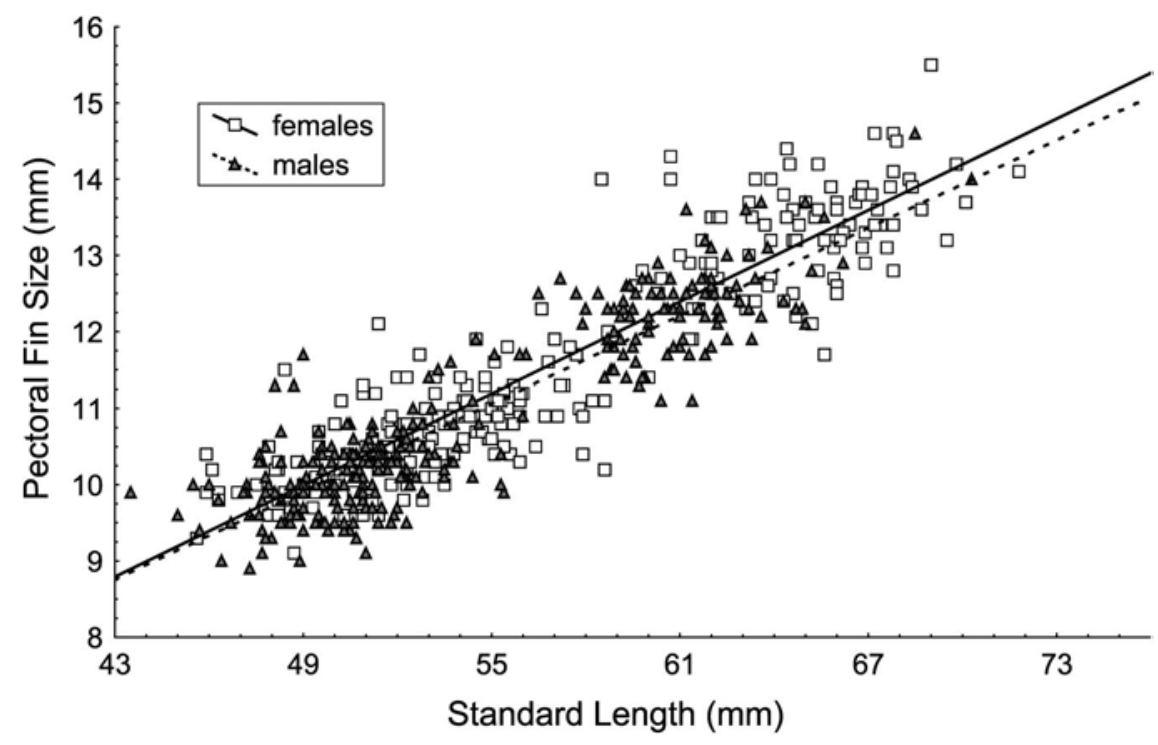

FIg. 2. Analysis of covariance for pectoral fin size. Standard length was used as a covariate controling for body size. Females have significantly larger fins than males of similar size $(P<0.001)$.

0.001, $\mathrm{df}=553$; SL: $F=2660.951, P<0.001$, df $=553)$. However, in contrast to what was found by Brønseth and Folstad (1997) and by Bakker and Mundwiler (1999), females had significantly larger fins than males when controlling for body size (least square mean ! SE: females $=11.346$ ! 0.032 ; males $=11.165$ 【 0.034 ). The same result was obtained by comparing the residuals of a linear regression of pectoral fins on SL pooling both sexes (mean residuals ! $\mathrm{SE}$ : females $=0.082$ 】 0.032 , males $=-0.092$ 】 $0.034 ; F$ $=13.993, P<0.001, \mathrm{df}=553)$.

Using linear regression, we verified if parasite load had any effect on males' condition. There was a significant, albeit weak, negative relationship between parasite load and condition $\left(r^{2}=0.06, F=18.090, P<0.001\right.$, df $=278$; Fig.

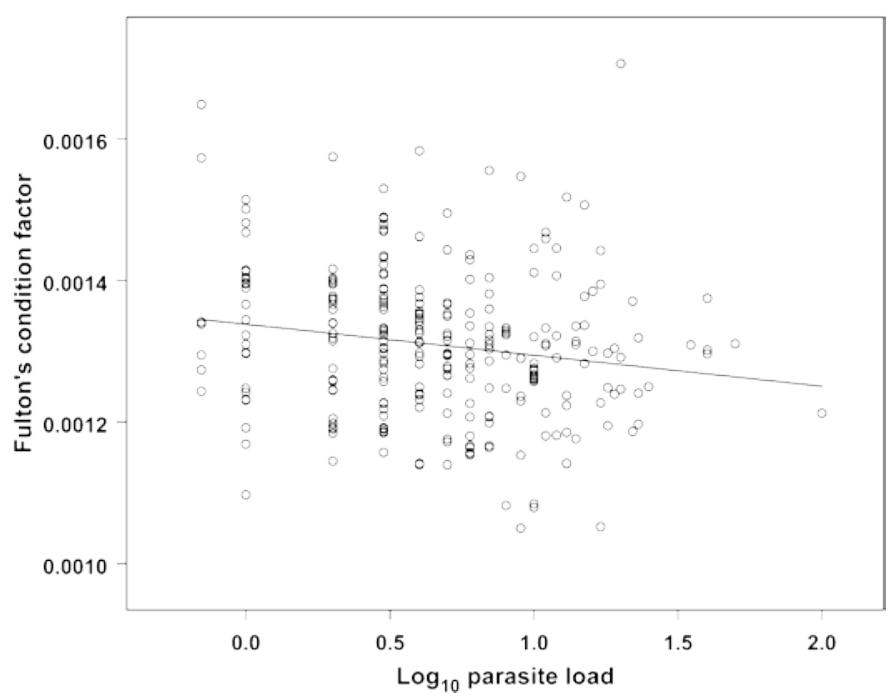

FIG. 3. Fulton's condition factor, log mass (g)/(log standard length $[\mathrm{mm}])^{3.18}$, as a function of log-transformed parasite load values (number of trematode metacercaria) for all males. $r^{2}=0.061 ; F=$ 18.090; $P<0.001 ; \mathrm{df}=278$.
3). Males had a significantly higher level of infection than females (mean log parasite load ! SE: females $=0.527$ ! 0.029 , males $=0.651$ ! 0.029 ; $t$-test: $t=-3.070, P<0.01$, $\mathrm{df}=566$ ), and territorial males with a nonzero mating success had significantly lower levels of infection than territorial males with a mating success of zero (mean log parasite load 【 SE: males with nonzero mating success $=0.601$ ! 0.061 , males with zero mating success $=0.831$ ! 0.053 ; $t$-test: $t=$ 2.754, $P<0.01$, df $=102$ ). Finally, standard length was compared within each of the two age classes, distinguished by the bimodal size distribution (Dufresne et al. 1990), between males and females as well as between territorial and nonterritorial males using Student's $t$-test. This analysis revealed that females were significantly larger than males within both age classes $(P<0.001)$ and that one-year-old territorial males were significantly larger than one-year-old nonterritorial males $(P<0.001)$. However, no significant difference was found between territorial and nonterritorial two-year-old males $(P>0.67)$.

\section{Regression Analyses and Surface Visualization}

The vector of linear coefficients obtained from the linear multiple regression including the five independent variables is presented in Table 2 . This analysis revealed a negative and significant effect of parasite load $(P<0.05)$. The estimates for all the other variables were nonsignificant, although the positive coefficient for mean $d^{2}$ also had a low $P$-value $(P$ $=0.115)$. The $y$ matrix of the quadratic regression is included in Table 2 and the $\mathbf{M}$ matrix is given in Table 3. The ç matrix revealed that there was a significant positive quadratic coefficients (concave selection) on distance to shore $(P<0.05)$. The canonical rotation identified two major axes of the surface $\left(m_{1}\right.$ and $\left.m_{5}\right), m_{1}$ essentially represented distance to shore, while $m_{5}$ reflected mostly the effect of parasite load. $m_{1}$ had a positive eigenvalue $(P=0.013)$, while the eigenvalue of $m_{5}$ was negative $(P=0.059)$, indicating that the stationary point of the surface was a saddle point. 
TABLE 2. The vector of linear regression coefficients $(p)$ and the ç matrix of quadratic (main diagonal) and cross-product terms for the analysis including all territorial males with complete measurements and the five variables. Linear and quadratic coefficients were estimated in separate regressions under a log-linear model for response with Poisson distribution and a scale parameter estimated by Pearson's chi-square divided by degrees of freedom. Standard errors are given in parentheses. $N=95$.

\begin{tabular}{lccccc}
\hline \hline & $p$ & Mean $d^{2}$ & Parasite load & $\begin{array}{c}\text { Distance to } \\
\text { shore }\end{array}$ & $\begin{array}{c}\text { Pectoral fin } \\
\text { size }\end{array}$ \\
\hline Mean $d^{2}$ & $-0.244(0.158)$ & $-0.108(0.124)$ & & & \\
Parasite load & $-0.298^{*}(0.158)$ & $-0.232(0.224)$ & $-0.208(0.185)$ & & \\
Distance to shore & $-0.137(0.160)$ & $-0.130(0.186)$ & $-0.224(0.187)$ & $0.280^{*}(0.138)$ & \\
Standard length & $0.185(0.149)$ & $-0.268(0.237)$ & $-0.017(0.224)$ & $0.186(0.183)$ & $-0.094(0.276)$ \\
Pectoral fin size & $0.061(0.150)$ & $0.216(0.274)$ & $0.181(0.224)$ & $-0.004(0.193)$ & $0.153(0.218)$ \\
\hline
\end{tabular}

* $P$ Š 0.05 .

The surface visualizations along $m_{1}$ and $m_{5}$ are presented in Figure 4, and the spline surface bounded by the $95 \%$ confidence interval in Figure 5. The thin-plate splines and the quadratic approximation were relatively similar in the sense that both were saddle shaped, but the spline surface was more rugged. Examination of the surfaces revealed that highest mating success was achieved by males located at both extremes of $m_{1}$. Extreme values of $m_{1}$ correspond mostly to males having nests located either close to the shore (in shallow waters associated with dense vegetation) or far from the shore (in deep water characterized by an absence of vegetation). The significant negative quadratic coefficient associated with $m_{5}$ suggests that highest mating success was generally achieved by males with intermediate values of parasite load (Fig. 4), although the ruggedness and wideness of the upper bound of the spline surface (Fig. 5) makes it difficult to firmly conclude on the trend.

We could not strictly rule out the possibility that some of the territorial males without eggs were part of a subsequent breeding cycle (in statistical terms, these males were not "structural zeroes" but "sampling zeroes"; Bishop et al. 1975) and so had not yet received eggs simply because they had not yet or had just started to court females. Consequently, including these males in the analysis might have artificially increased the noise of the data and hence the probability of Type II error. Therefore, we repeated the analysis, this time excluding the males with a mating success of zero, focusing instead on males for which realized mating success and breeding status could be unambiguously determined (by examination of eggs developmental stages).

The vector of linear coefficients obtained from this linear multiple regression including the five independent variables is presented in Table 4. This analysis revealed no significant linear association between any of the traits and mating success (all $P$-values $>0.485$ ). Reducing the number of males in the analysis also reduced the number of estimated parameters that could be included in the quadratic regression from five to three to minimize overfitting (Schaffer 1993). Hence, we first combined SL and pectoral fins in a single variable by using their first principal component (referred as body size hereafter). This first principal component explained more than $94 \%$ of the variance in both traits (factor loading: 0.707 for fin size; 0.707 for SL). We then restricted the quadratic analysis to three variables at a time. Thus, four different ç matrices were obtained, corresponding to the four possible three variables combinations.

No significant effect was identified for body size in the ç matrix of any of the three variable combinations in which it was involved (see Appendix 2 available online at http:// dx.doi.org/10.1554/04-189.1.s1). Therefore, we focus on the three other variables (parasite load, distance to shore, mean $d^{2}$ ) for which the ç matrix is presented in Table 4 and the $\mathbf{M}$ matrix in Table 5. The ç matrix revealed that there were significant quadratic coefficients on parasite load $(P=0.002)$ and distance to shore $(P=0.014)$. In addition, there were significant interaction coefficients involving distance to shore and mean $d^{2}(P<0.001)$ and distance to shore and parasite load $(P=0.010)$. The canonical rotation identified two major axes of the surface $\left(m_{1}\right.$ and $\left.m_{3}\right) . m_{1}$ comprised mostly distance to shore and, to a lesser extant, mean $d^{2}$ while $m_{3}$ essentially represented parasite load. $m_{1}$ had a positive eigenvalue $(P<$ $0.001)$, while the eigenvalue of $m_{3}$ was negative $(P<0.001)$, indicating that the stationary point of the surface was a saddle point.

The surface visualizations along $m_{1}$ and $m_{3}$ are presented in Figure 6, and the spline surface bounded by the 95\% confidence interval in Figure 7 . The thin-plate splines and the quadratic approximation both resulted in a similar saddleshaped surface. As in the case of the analysis including all territorial males, the surfaces revealed that highest mating

TABle 3. The M matrix of eigenvectors $\left(m_{i}\right)$ and eigenvalues (hi) from the canonical analysis of the ç matrix including all territorial males with complete measurements and the five variables. Standard errors are given in parentheses. $N=95$.

\begin{tabular}{lcrrrr}
\hline & & & & & \\
$\mathrm{h}_{i}$ & Mean $d^{2}$ & Pectoral fins & Standard length & $\begin{array}{c}\text { Distance to } \\
\text { shore }\end{array}$ \\
\hline$m_{1}$ & $0.320^{* *}(0.125)$ & 0.0615 & 0.007 & 0.201 & -0.190 \\
$m_{2}$ & $0.231(0.170)$ & 0.870 & 0.279 & -0.290 & 0.959 \\
$m_{3}$ & $-0.015(0.210)$ & -0.085 & 0.684 & 0.661 & 0.058 \\
$m_{4}$ & $-0.274(0.209)$ & 0.292 & -0.674 & 0.569 & 0.285 \\
$m_{5}$ & $-0.297^{*}(0.179)$ & -0.383 & -0.030 & -0.338 & 0.366 \\
\hline
\end{tabular}

\footnotetext{
*P $=0.059,{ }^{* *} P<0.05$.
} 

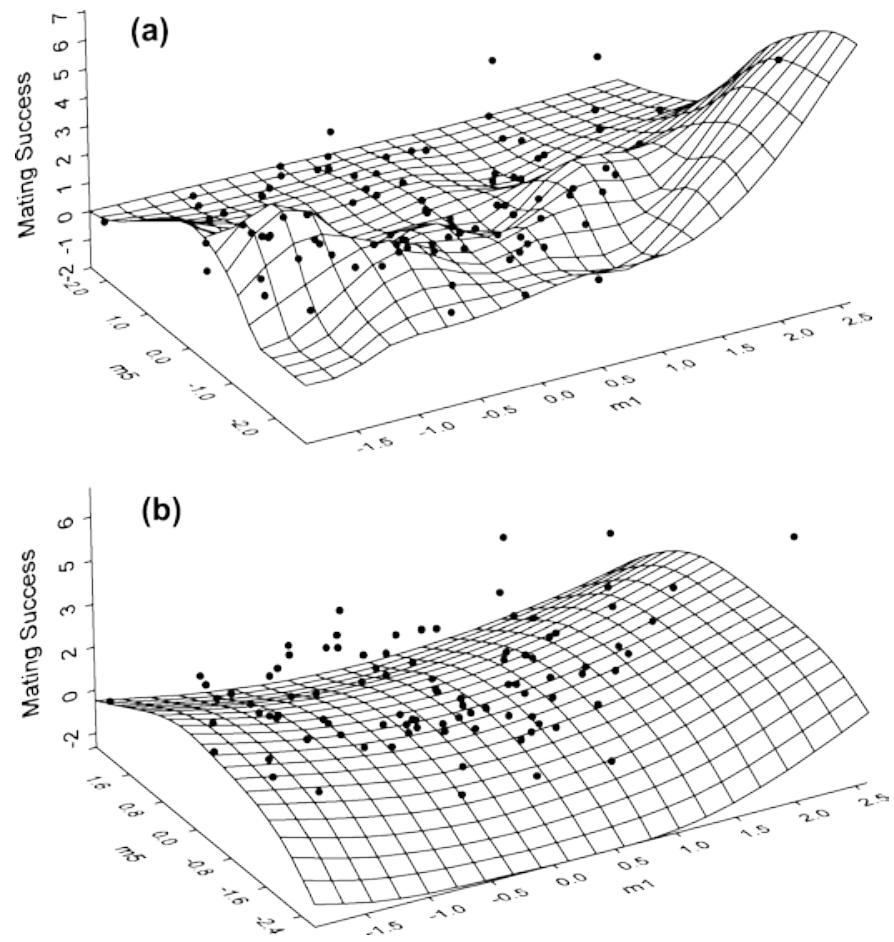

FIg. 4. Fitness surface visualized by thin-plate splines (a) and the best quadratic approximation (b), along the two significant axes of selection $\left(m_{1}\right.$ and $\left.m_{5}\right)$ identified by the canonical rotation of the ç matrix (values are standardized) from the analysis including all territorial males with complete measurement on all independent variables $(N=95)$. The points represent the original observed values. success was achieved by males located at both extremes of $m_{1}$ and intermediate values of $m_{3}$ representing intermediate values of parasite load. Qualitative conclusions from the two analyses are therefore very similar.

\section{Discussion}

The role of nonlinear selection, whether stabilizing or disruptive, is central in models of adaptation and adaptive landscape, the maintenance of genetic variance in quantitative traits, and speciation (Kingsolver et al. 2001; Zhang and Hill 2003; Arnegard and Kondrashov 2004). Nevertheless, field studies suggest that directional selection is more important and more common. In Kingsolver et al.'s (2001) review, for instance, 25\% of 993 directional selection gradients were significant at the 0.05 level, while this proportion was only $16 \%$ for the 574 quadratic selection gradients. However, the detection of nonlinear selection can be hampered by the presence of correlational selection if the canonical rotation of the ç matrix is not performed (Blows and Brooks 2003). Because this step is rarely taken, nonlinear selection in the wild is probably underestimated (Blows and Brooks 2003). The results of the present study show that male mating success was related by significant linear and nonlinear relationships with various traits, while significant correlational effects were also detected. Below, we discuss the evolutionary consequences of these findings as well as the potential usefulness of considering nonlinear relationships between mating success and these type of traits in future studies.

\section{Mating Success Fitness Surface}

Recent data suggested that selection through mate choice might be stronger than selection through viability or fecundity (Kingsolver et al. 2001). This possibility emphasizes the importance of documenting the effects of mate choice in the wild to understand adaptive evolution. A crucial step to reach

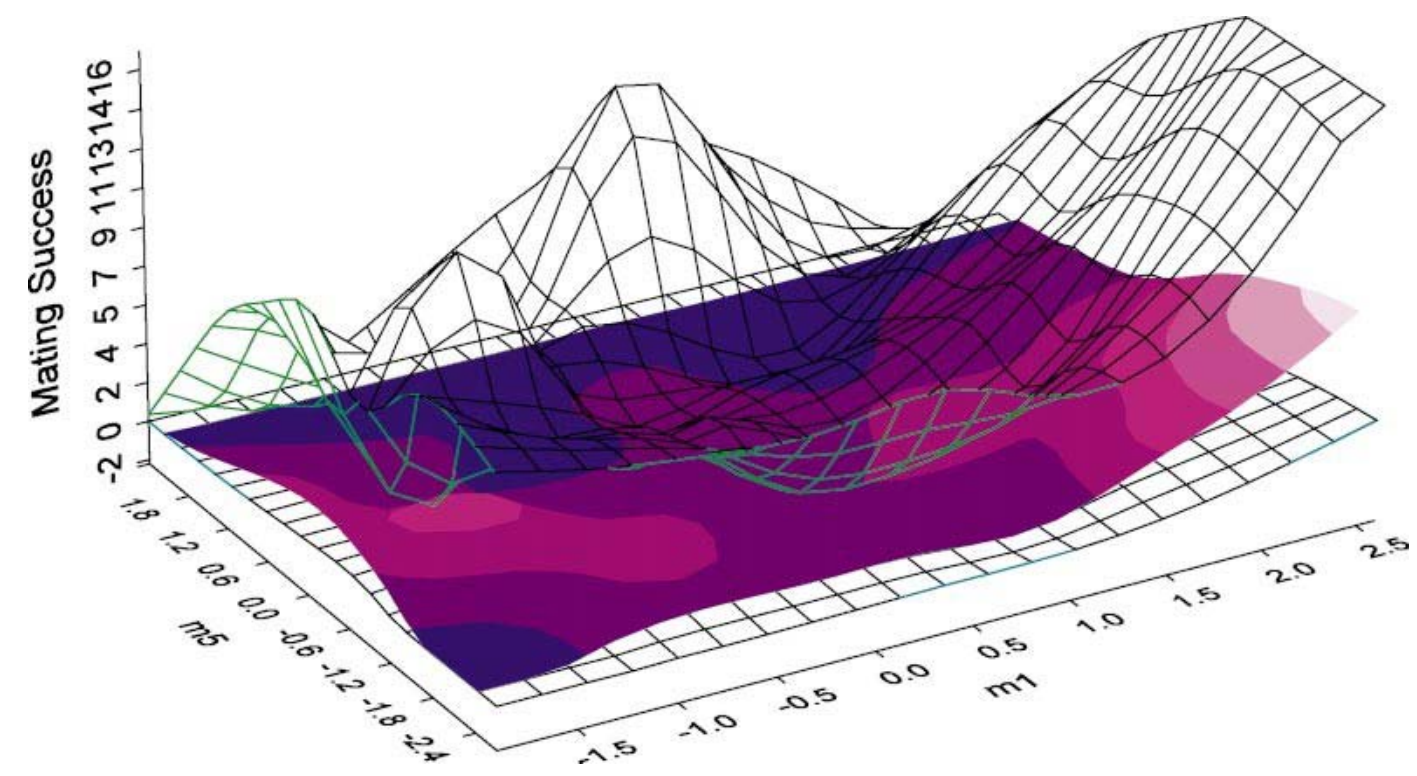

FIG. 5. Fitness surface visualized by thin-plate splines along the two major axes of selection $\left(m_{1}\right.$ and $\left.m_{5}\right)$ identified by the canonical rotation of the ç matrix (values are standardized) from the analysis including all territorial males with complete measurement on all independent variables $(N=95)$, with upper and lower bounds (transparent grids) of the 95\% Bayesian confidence interval. 
TABLE 4. Vector of linear regression coefficients ( $p$ ), and the matrix of quadratic (main diagonal) and cross-product terms for the analysis including only males with a nonzero mating success. Standard length and pectoral fin size were excluded of the quadratic analysis (see Results). Linear and quadratic coefficients were estimated in separate regressions under a log-linear model for response with Poisson distribution and a scale parameter correcting for underdispersion. Standard errors are given in parentheses. $N=37$.

\begin{tabular}{lllll}
\hline \hline & $p$ & & Mean $d^{2}$ & Parasite load \\
\hline Mean $d^{2}$ & $0.065(0.093)$ & mean $d^{2}$ & $0.022(0.058)$ & Distance to shore \\
Parasite load & $0.038(0.096)$ & parasite load & $0.123(0.091)$ & $-0.288^{* *}(0.096)$ \\
Distance to shore & $0.005(0.096)$ & nest site choice & $0.339 \dagger(0.089)$ & $-0.179 *(0.072)$ \\
Standard length & $0.046(0.095)$ & & & $0.194^{*}(0.079)$ \\
Pectoral fin size & $0.027(0.094)$ & & & \\
\hline
\end{tabular}

$* P<0.05 ; * * P<0.01 . \dagger P<0.001$.

this goal is to document the shape and strength of the relationships linking female mate choice to various male traits in natural conditions. Female mate preferences are typically seen as open-ended (Price 1998; Sherman and Reeve 1999), therefore leading to exaggeration of secondary sexual traits (Hall et al. 2000). As a result, directional selection is often expected in studies of sexual selection through mate choice (e.g., FitzGerald et al. 1994; Pomiankowski and Møller 1995; Kraak et al. 1999b; Brooks and Endler 2001), as those usually focus on secondary sexual traits. However, mate preferences for conspicuous dimorphic signal traits might have complex indirect consequences on many other traits. Besides, one cannot rule out a priori that other types of traits may also be directly assessed in mate choice.

In our analysis that included all territorial males, evidence of linear relationships between mating success and the measured traits could be detected for only one variable (parasite load) while significant quadratic effects were detected in both the $\mathbf{y}$ and $\mathbf{M}$ matrices. In the analysis including only males with a nonzero mating success, the results indicated that the effect of female mate choice on the male traits analyzed was only nonlinear. Indeed, even before the canonical rotation of the axes, two quadratic coefficients out of three were significant. In addition, there was evidence of significant interactions among two of the three traits. The finding of significant correlational gradients is noteworthy because those are seldomly reported, and thus very little is known about correlational selection in the wild (Kingsolver et al. 2001).

These significant interactions involved traits that do not seem to be directly functionally related (distance to shore $x$ mean $d^{2}$ and distance to shore $\times$ parasite load), although they may all affect fitness. Hence, females' mate assessment appears to have affected different types of traits simultaneously and the effects of the males' trait values were not acting independently of each other, irrespective of their apparent functional relationships. This suggest that individual males'

TABle 5. The $\mathbf{M}$ matrix of eigenvectors $\left(m_{I}\right)$ and eigenvalues $\left(\mathrm{h}_{I}\right)$ from the canonical analysis of the ç matrix including only males with a nonzero mating success. Standard errors are given in parentheses. $N=37$.

\begin{tabular}{|c|c|c|c|c|}
\hline & $h_{i}$ & Mean $d^{2}$ & $\begin{array}{c}\text { Parasite } \\
\text { load }\end{array}$ & $\begin{array}{l}\text { Distance to } \\
\text { shore }\end{array}$ \\
\hline$m_{1}$ & $0.302 \dagger(0.076)$ & 0.504 & -0.078 & 0.860 \\
\hline$m_{2}$ & $-0.043(0.063)$ & 0.834 & 0.339 & -0.435 \\
\hline$m_{3}$ & $-0.331 \dagger(0.091)$ & -0.280 & 0.927 & 0.249 \\
\hline
\end{tabular}

total attractiveness was not simply additively related to these traits, but depended instead on the balance of all trait values following some particular, possibly context-dependant, combination rules.

The linear regression of the full analysis (including all territorial males with complete measurement) indicated a negative significant effect of parasite load, suggesting that males with lower levels of infection were favored by females. However, the canonical rotation of y identified two main axes

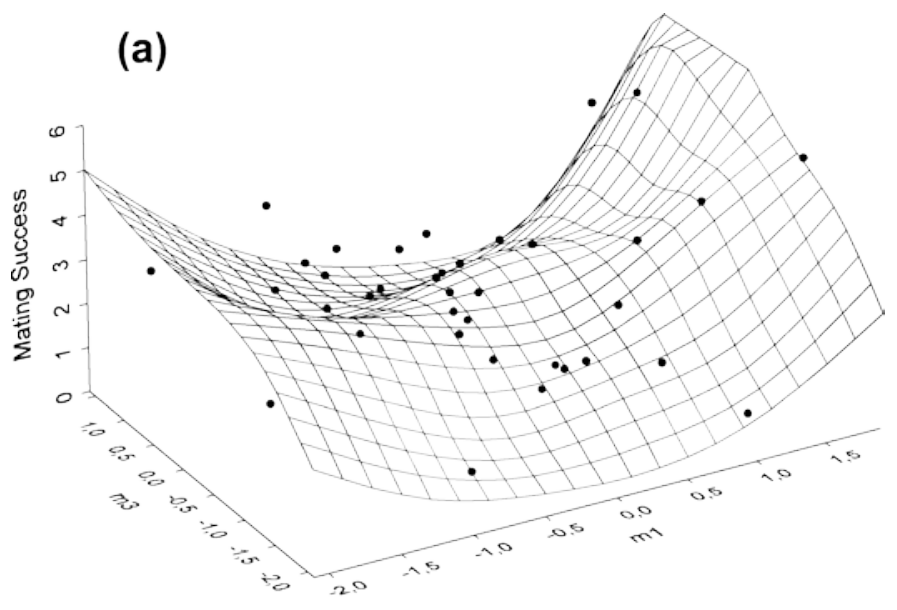

(b)

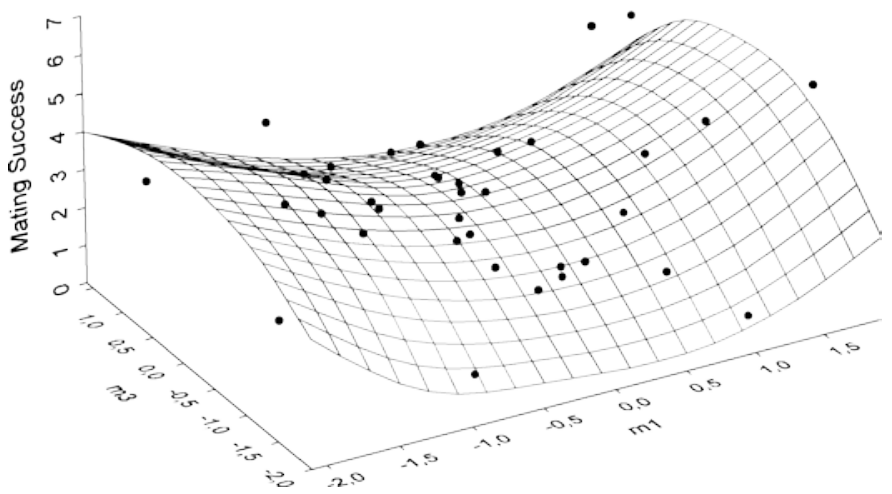

FIG. 6. Fitness surface visualized by thin-plate splines (a) and the best quadratic approximation (b), along the two significant axes of selection $\left(m_{1}\right.$ and $\left.m_{3}\right)$ identitied by the canonical rotation of the $c$ matrix (values are standardized) from the analysis including only

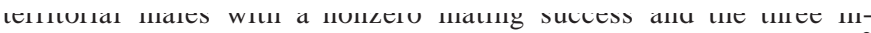
dependent variables distance to shore, parasite load, and mean $d^{2}$ $(N=37)$. The points represent the original observed values. 


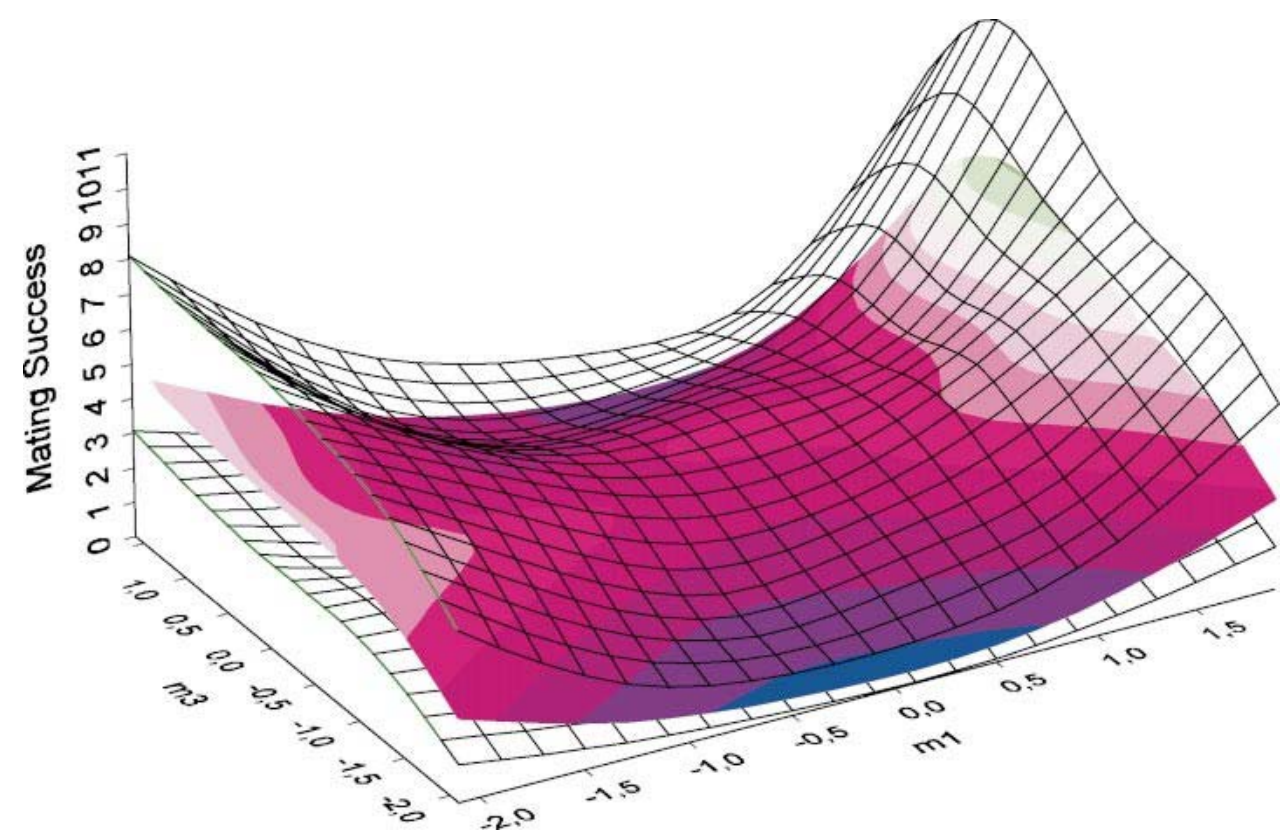

FIG. 7. Fitness surface visualized by thin-plate splines along the two major axes of selection $\left(m_{1}\right.$ and $\left.m_{5}\right)$ identified by the canonical rotation of the ç matrix (values are standardized) from the analysis including only territorial males with a nonzero mating success and the three independent variables distance to shore, parasite load, and mean $d^{2}(N=37)$, with upper and lower bounds (transparent grids) of the $95 \%$ Bayesian confidence interval.

of selection $\left(m_{1}\right.$ and $\left.m_{5}\right)$ of which $m_{5}$ represented mostly parasite load. $m_{5}$ had a signficant negative eigenvalue of the same magnitude than the linear coefficient for parasite load, indicating convex selection on this trait. It seems at first difficult to decide which effect is more important. But the similar quadratic estimate for the same trait in the analysis including only males with a nonzero mating success coupled with the absence of linear effect of parasite load in this latter analysis might provide some clue about the reason of this apparently mixed pattern. It seems possible that, past a certain level of infection, males are simply in too poor condition to efficiently court females, which could also explain why mean parasite load was significantly higher in males with zero mating success. Otherwise, mating success could be higher for males having intermediate levels of infection. The relationship between parasite load and mating success might not be very stable, however, as examination of the two matrices involving body size and parasite load for the analysis of males with nonzero mating success (Appendix 2, available online) shows that this estimate was nonsignificant in these two cases. Admittedly, this could reflect the limited power of this analysis and consequently, further investigations will be required for clarifying the nature of the relationship between this trait and mating success in this population.

If the convex component of selection on parasite load is real, however, alternative mechanism linking mate choice, immunocompetence, and sexual signals might need to be proposed, as the existing theory do not explicitly predict stabilizing outcomes on parasite load (Getty 2002). Models of honest signaling through the well-documented androgens immunosuppressive effect in vertebrates (Folstad and Karter 1992; Zuk and McKean 1996; Peters 2000), which propose that male investment in attractiveness to females involves costs in immunity, which in turn are reflected by increased level of infection (Zuk and McKean 1996), may represent a promising avenue to explore the possibility of nonlinear effects on parasite load at equilibrium. Such models also predict the significantly higher level of parasite infection in males than in females revealed by our results (Zuk and McKean 1996).

Males' nest site choice, in contrast, was more clearly related to mating success by a significant positive quadratic coefficient acting on $m_{1}$, which essentially reflected nest distance to shore. This relationship was consistently found in all analyses (both the full one and the nonzero males analysis) and appears to be stable. The higher mating success obtained by males having established their nest either close to the shore or far from the shore as compared to males nesting at intermediate locations may reflect a female preference to spawn with males nesting in areas less accessible to conspecific and bird predators (such as the great blue heron), as this could decrease the risk of predation on both their progeny and the male guarding it. Indeed, vegetation cover is dense and offers concealment in shallow waters close to the shore (Lachance and FitzGerald 1992), whereas deeper waters are likely to be inaccessible to predatory birds (Gawlik 2002), since depth typically reaches more than $1 \mathrm{~m}$ in the middle of the pool (J. Blais, pers. obs.). Great blue herons, for instance, cannot feed at depths greater than $39 \mathrm{~cm}$ (Powell 1987). At intermediate distances from the shore, however, vegetation cover is reduced and water depth may allow birds to feed on nesting males. Alternatively, the pattern could be indirect if more attractive males have a competitive advantage over less attractive ones and secure territories offering concealment and protection.

Thus, it appears that males have at least two nest-site- 
choice tactics optimizing their mating success in this system. This raises the possibility of multiple adaptive peaks on males' fitness surface, a phenomenon also recently detected by Blows et al. (2003) for male guppies attractiveness measured in the laboratory. Concave selection on a behavioral trait such as males' nest site choice induced by female mate preference is interesting since examples of disruptive effects of mate choice are lacking and is an important aspect of models of sympatric speciation by sexual selection (Arnegard and Kondrashov 2004). The pattern reported in this study is not a demonstration of the kind of opposite and extreme variation in preference typically required by such models (Turner and Burrows 1995; Higashi et al. 1999; Takimoto et al. 2000), but nevertheless illustrates that it is possible for males of a population to obtain equally high mating success despite displaying different trait values (a behavioral trait in the present case). Even if nest site choice may aim at ultimately maximizing the same characteristic (here protection from predators), from the female perspective, there are still multiple alternatives. However, male-male competition probably plays a role in territory establishment, and this is supported by our data on male body size (see also Candolin and Voigt 2003). It this thus also possible that the observed pattern is due to the fact that males that are more attractive to females are also the most competitive ones and are able to secure territories providing shelter from predators for their own benefits.

The positive linear term representing mean $d^{2}$ in the full analysis, despite being nonsignificant, had a relatively low $P$-value of 0.115 , and the vector $m_{1}$ in the analysis of nonzero males also comprised a minor component representing mean $d^{2}$, and thus mating success along this axis reflects an effect of both traits. These observations may therefore provide the third empirical evidence of a relationship between mean $d^{2}$ and mating success (see Höglund et al. 2002; Neff 2004). Namely, Neff (2004) recently showed that female bluegill sunfish (Lepomis macrochirus) were choosing their mates to produce offsprings lying at an intermediate position along the inbreeding/outbreeding continuum measured by mean $d^{2}$ calculated over 11 loci. Mean $d^{2}$ is thought to be a reliable index of inbreeding having occured deep in the pedigree, especially when the mutation rate and population sizes are high (Tsitrone et al. 2001). Considering the high level of variability of the loci examined and population sizes typical for this kind of fish species (Neff 2004), if overdomiance, inbreeding depression, or outbreeding depression affect traits influencing female mating decision (e.g., MHC genotypes; Reusch et al. 2001; Aeschlimann et al. 2003; Neff 2004), mean $d^{2}$ could reveal these effects.

\section{Limitations of the Study}

It is important to identify the potential limitations of this study as those could undermine the robustness of the conclusions one might draw. As mentioned previously, sample size is often an issue in selection studies, and this case is no exception. Sample size mostly affects power to detect weak effects, thereby increasing the probability of Type II error. Here, because we detected several significant effects, this problem does not seem to have been critical, although weak effects might have been missed. On the other hand, sample size can also affect the repeatability of the results if the effects detected are more due to noise than real relationships (overfitting), which could increase the probability of Type I error. It is difficult to assess how much these two potential problems might affect our results and their relative importance. However, the two different analyses (the one including all territorial males and the one including only males with a nonzero mating success) generally produced similar results, and estimates that were always of the same sign. Nevertheless, in the analysis including only males with nonzero mating success, the effect of parasite load was nonsignificant when analyzed with body size. This might reflect instability related to either of the two limitations mentioned above.

Another possible confounding factor is the fact that male investment in current and future reproduction could modify the relationships detected here if individual males vary greatly in their success at attracting females in successive breeding cycles. In other words, the selection caused by mate choice on the measured traits could fluctuate through time. However, males of this population live only two years, and most of them complete only one breeding cycle per year (Lachance and FitzGerald 1992). Finally, egg cannibalism could have also led to the underestimation of some males' mating success. How this would affect the results is not immediately clear, but seems at this point unlikely to dramatically change the detected relationships. Nevertheless, given these possible complications, firmer conclusions on the ultimate evolutionary consequences of the effects detected on any particular trait must await temporal replications of the study.

\section{Conclusions}

The lack of evidence for linear selection found by this study might not be surprising, considering the direction of size dimorphism characterized by females being larger in terms of both SL and pectoral fin size in this population and the fact that we excluded males' dimorphic nuptial coloration, for which a greater intensity has sometimes, but not consistantly (e.g., Kraak et al. 1999b; Braithwaite and Barber 2000) been found to be preferred by females threespine stickleback (Milinski and Bakker 1990; Bakker and Milinski 1993). Females' open-ended preference for more intense male ornamentation used as proximate cue in mate choice may induce complex indirect nonlinear selection on various traits such as those observed here due to correlation patterns with the display trait. Such indirect relationships between mate choice and various characters have important implications but their roles remain controversial (Hunt et al. 2004). The relative evolutionary impact of sexual selection beyond exageration of secondary sexual traits and its role in speciation depends on the presence, strength, and shape of these effects. Our results suggest that mate choice might indeed have important consequences on many different traits, perhaps mostly through nonlinear relationships. The presence of nonlinear selection on an organism's fitness surface has also profound consequences (e.g., on the evolutionary stability of the Gmatrix [Blows et al. 2004], and the maintenance of a population at or near its adaptive peak). Hence, finding evidence 
of stabilizing effects of sexual selection provides important insight into the role this process might play in this context.

\section{ACKNOWLEDGMENTS}

We are grateful to the late G. J. FitzGerald for having recognized the potential and developed the scientific interest for the Gasterosteus aculeatus anadromous population of the Isle-Verte coastal tide pools system. We thank R. Brooks and two anonymous reviewers for helpful comments on earlier versions of the manuscript. This work was supported by the Canadian Research Chair in conservation genetics of aquatic organisms and a research grant from the Natural Science and Engineering Council (NSERC, Canada) to LB. JB was supported by a Fond de Recherche sur la Nature et les Technologies du Québec postgraduate scholarship.

\section{Literature Cited}

Aeschlimann, P. B., M. A. Haberli, T. B. H. Reusch, T. Boehm, and M. Milinski. 2003. Female sticklebacks Gasterosteus aculeatus use self-reference to optimize MHC allele number during mate selection. Behav. Ecol. Sociobiol. 54:119-126.

Arnegard, M. E., and A. S. Kondrashov. 2004. Sympatric speciation by sexual selection alone is unlikely. Evolution 58:222-237.

Bakker, T. C. M., and M. Milinski. 1993. The advantages of being red: sexual selection in the stickleback. Mar. Behav. Physiol. 23:287-300.

Bakker, T. C. M., and B. Mundwiler. 1999. Pectoral fin size in a fish species with paternal care: a condition-dependent sexual trait revealing infection status. Freshwater Biol. 41:543-551.

Bell, M. A., and S. A. Foster. 1994. The evolutionary biology of the threespine stickleback. Oxford Univ. Press, Oxford, U.K.

Bishop, Y. M. M., S. E. Fienberg., and P. W. Holland. 1975. Discrete multivariate analysis: theory and practice. MIT Press, Cambridge, MA.

Blanckenhorn, W. U., U. R. S. Kraushaar, Y. Teuschl, and C. T. Reim. 2004. Sexual selection on morphological and physiological traits and fluctuating asymmetry in the black scavenger fly Sepsis cynipsea. J. Evol. Biol. 17:629-641.

Blows, M. W., and R. Brooks. 2003. Measuring non-linear selection. Am. Nat. 162:815-820.

Blows, M. W., R. Brooks, and P. G. Kraft. 2003. Exploring complex fitness surfaces: multiple ornamentation and polymorphism in male guppies. Evolution 57:1622-1630.

Blows, M. W., S. F. Chenoweth, and E. Hine. 2004. Orientation of the genetic variance-covariance matrix and the fitness surface for multiple male sexually selected traits. Am. Nat. 163: 329-340.

Braithwaite, V. A., and I. Barber. 2000. Limitations to colour-based sexual preferences in three-spined sticklebacks. Behav. Ecol. Sociobiol. 47:413-416.

Brønseth, T., and I. Folstad. 1997. The effect of parasites on courtship dance in threespine sticklebacks: more than meets the eye? Can. J. Zool. 75:589-594.

Brooks, R., and J. A. Endler. 2001. Direct and indirect sexual selection and quantitative genetics of male traits in guppies (Poecilia reticulata) . Evolution 55:1002-1015.

Candolin, U., and H.-R. Voigt. 2001. No effect of a parasite on reproduction in stickleback males: a laboratory artefact? Parasitology 122:457-464.

— 2003 . Size-dependent selection on arrival times in sticklebacks: why small males arrive first. Evolution 57:862-871.

Coltman, D. W., and J. Slate. 2003. Microsatellite measures of inbreeding: a meta-analysis. Evolution 57:971-983.

Coltman, D. W., J. G. Pilkington, J. A. Smith, and J. M. Pemberton. 1998. Birth weight and neonatal survival of harbour seal pups are positively correlated with genetic variation measured by microsatellites. Proc. R. Soc. Lond. B. Biol. Sci. 265:803-809.
Côté, I. M., and W. Hunte. 1989. Male and female mate choice in the redlip blenny: why bigger is better. Anim. Behav. 38:78-88.

Coulson, T. N., J. M. Pemberton, S. D. Albon, M. Beaumont, T. C. Marshall, J. Slate, F. E. Guinness, and T. H. Clutton-Brock. 1998. Microsatellites reveal heterosis in red deer. Proc. R. Soc. Lond. B. Biol. Sci. 265:489-495.

David, P. 1998. Heterozygosity-fitness correlations: new perspective on old problems. Heredity 80:531-537.

DeWoody, J. A., D. Walker, and J. C. Avise. 2000. Genetic parentage in large half-sib clutches: theoretical estimates and empirical appraisals. Genetics 154:1907-1912.

Doucet, S. M., and R. Montgomerie. 2003. Multiple sexual ornaments in satin bowerbirds: ultraviolet plumage and bowers signal different aspects of male quality. Behav. Ecol. 14:503-509.

Dufresne, F., G. J. FitzGerald, and S. Lachance. 1990. Age and size-related differences in reproductive success and reproductive costs in threespine sticklebacks (Gasterosteus aculeatus). Behav. Ecol. 1:140-147.

FitzGerald, G. J. 1983. The reproductive ecology and behaviour of three sympatric sticklebacks (Gasterosteidae) in a saltmarsh. Biol. Behav. 8:67-79.

FitzGerald, G. J., and N. Van-Havre. 1987. The adaptive significance of cannibalism in sticklebacks (Gasterosteidae: Pisces). Behav. Ecol. Sociobiol. 20:125-128.

FitzGerald, G. J., M. Fournier, and J. Morrissette. 1994. Sexual selection in an anadromous population of threespine sticklebacks: no role for parasites. Evol. Ecol. 8:348-356.

Folstad, I., and A. J. Karter. 1992. Parasites, bright males, and the immunocompetence handicap. Am. Nat. 139:603-622.

Gawlik, D. E. 2002. The effects of prey availability on the numerical response of wading birds. Ecol. Monogr. 72:329-346.

Getty, T. 2002. Signalling health versus parasites. Am. Nat. 159: 363-371.

Goldstein, D. B., A. R. Linares, L. L. Cavalli-Sforza, and M. Feldman. 1995. An evaluation of genetic distances for use with microsatellite loci. Genetics 139:463-471.

Hall, D. W., M. Kirkpatrick, and B. West. 2000. Runaway sexual selection when female preferences are directly selected. Evolution 54:1862-1869.

Hamilton, W. D., and M. Zuk. 1982. Heritable true fitness and bright birds: a role for parasites? Science 218:384-387.

Health, D. D., C. A. Bryden, J. M. Shrimpton, G. K. Iwama, J. Kelly, and J. W. Heath. 2002. Relationships between heterozygosity, allelic distance $\left(d^{2}\right)$, and reproductive traits in chinook salmon, Oncorhynchus tshawytscha. Can. J. Fish. Aquat. Sci. 59: 77-84.

Hersch, E. I., and P. C. Phillips. 2004. Power and potential bias in field studies of natural selection. Evolution 58:479-485.

Higashi, M., G. Takimoto, and N. Yamamura. 1999. Sympatric speciation by sexual selection. Nature 402:523-536.

Höglund, J., S. B. Piertney, R. V. Alatalo, J. Lindell, A. Lundberg, and P. T. Rintamäki. 2002. Inbreeding depression and male fitness in black grouse. Proc. R. Soc. Lond. B. Biol. Sci. 269: $711-715$.

Hunt, J., L. F. Bussière, M. D. Jennions, and R. Brooks. 2004. What is genetic quality? Trends Ecol. Evol. 19:329-333.

Jamieson, I. G., D. M. Blouw, and P. W. Colgan. 1992. Parental care as a constraint on male mating success in fishes: a comparative study of threespine and white sticklebacks. Can. J. Zool. 70:956-962.

Johnstone, R. A. 1995. Honest advertisement of multiple qualities using multiple signals. J. Theor. Biol. 177:87-94.

Jones, A. G., S. Östlund-Nilsson, and J. C. Avise. 1998. A microsatellite assessment of sneaked fertilization and egg thievery in the fifteenspine stickleback. Evolution 5:848-858.

Kingsolver, J. G., H. E. Hoekstra, J. M. Hoekstra, D. Berrigan, S. N. Vignieri, C. E. Hill, A. Hoang, P. Gibert, and P. Beerli. 2001. The strength of phenotypic selection in natural populations. Am. Nat. 157:245-261.

Kirkpatrick, M., and S. L. Nuismer. 2004. Sexual selection can constrain sympatric speciation. Proc. R. Soc. Lond. B. Biol. Sci. 271:687-693.

Kraak, S. B. M., and T. C. M. Bakker. 1998. Mutual mate choice 
in sticklebacks: attractive males choose big females, which lay big eggs. Anim. Behav. 56:859-866.

Kraak, S. B. M., T. C. M. Bakker, and B. Mundwiler. 1999a. Correlates of the duration of the egg collecting phase in the threespined stickleback. J. Fish Biol. 54:1038-1049.

- 1999b. Sexual selection in sticklebacks in the field: correlates of reproductive, mating, and paternal success. Behav. Ecol. 10:696-706.

Künzler, R., and T. C. M. Bakker. 2000. Pectoral fin size and paternal quality in sticklebacks. Proc. R. Soc. Lond. B. Biol. Sci. 267:999-1004.

Lachance, S., and G. J. Fitzgerald. 1992. Parental care tactics of three-spined sticklebacks living in a harsh environment. Behav. Ecol. 3:360-366.

Lande, R., and S. J. Arnold. 1983. The measurement of selection on correlated characters. Evolution 37:1210-1226.

Lemly, A. D., and G. W. Esch. 1984. Effects of the trematode Uvulilfer ambloplitis on juvenile bluegill sunfish, Lepomis macrochirus: ecological implications. J. Parasitol. 70:475-492.

Marshall, T. C., and J. A. Spalton. 2000. Simultaneous inbreeding and outbreeding depression in reintroduced Arabian oryx. Anim. Conserv. 3:241-248.

McCullagh, P., and J. Nelder. 1989. Generalized linear models. Chapman and Hall, London.

McKinnon, J. S., S. Mori, B. K. Blackman, L. David, D. M. Kingsley, L. Jamieson, J. Chou, and D. Schluter. 2004. Evidence for ecology's role in speciation. Nature 429:294-298.

Milinski, M., and T. C. M. Bakker. 1990. Female sticklebacks use male coloration in mate choice and hence avoid parasitized males. Nature 344:330-333.

Mori, S. 1994. Nest site choice by the three-spined stickleback, Gasterosteus aculeatus (form leiurus), in spring-fed waters. J. Fish Biol. 45:279-289.

Neff, B. D. 2004. Stabilizing selection on genomic divergence in a wild fish population. Proc. Natl. Acad. Sci. USA 101: 2381-2385.

Peichel, C. L., K. S. Nereng, K. A. Ohgi, B. L. E. Cole, P. F. Colosimo, C. A. Buerkle, D. Schluter, and D. M. Kingsley. 2001. The genetic architecture of divergence between threespine stickleback species. Nature 414:901-905.

Peters, A. 2000. Testosterone treatment is immunosuppressive in superb fairy-wrens, yet free-living males with high testosterone are more immunocompetent. Proc. R. Soc. Lond. B. Biol. Sci. 267:884-889.

Phillips, P. C., and S. J. Arnold. 1989. Visualizing multivariate selection. Evolution 43:1209-1222.

Pomiankowski, A., and A. P. Møller. 1995. A resolution of the lek paradox. Proc. R. Soc. Lond. B. Biol. Sci. 260:21-29.

Powell, G. V. N. 1987. Habitat use by wading birds in a subtropical estuary: implications of hydrography. Auk 104:740-749.

Price, T. 1998. Sexual selection and natural selection in bird speciation. Philos. Trans. R. Soc. Lond. B. Biol. Sci. 353:1-12.

Pryke, S. R., S. Andersson, and M. J. Lawes. 2001. Sexual selection of multiple handicaps in the red-collared widowbird: female choice of tail length but not carotenoid display. Evolution 55: 1452-1463.

Reusch, T. B. H., M. A. Häberli, P. B. Aeschlimann, and M. Milinski. 2001. Female sticklebacks count alleles in a strategy of sexual selection explaining MHC polymorphism. Nature 414: 300-302.
Rico, C., U. Kuhnlein, and G. J. FitzGerald. 1992. Male reproductive tactics in the threespine stickleback-an evaluation by DNA fingerprinting. Mol. Ecol 1:79-87.

Rico, C., D. Zadworny, U. Kuhnlein, and G. J. FitzGerald. 1993. Characterization of hypervariable microsatellite loci in the threespine stickleback Gasterosteus aculeatus. Mol. Ecol. 2: 271-272.

Rossiter, S. J., G. Jones, R. D. Ransome, and E. M. Barratt. 2001. Outbreeding increases offspring survival in wild greater horseshoe bats (Rhinolophus ferrumequinum). Proc. R. Soc. Lond. B. Biol. Sci. 268:1055-1061.

Rowland, W. J. 1995. Do female stickleback care about male courtship vigour? Manipulation of display tempo using video playback. Behaviour 132:951-961.

Schaffer, C. 1993. Overfitting avoidance as bias. Mach. Learn. 10: 153-178.

Schluter, D., and D. Nychka. 1994. Exploring fitness surfaces. Am. Nat. 143:597-616.

Saether, S. A., P. Fiske, J. A. Kalas, and J. M. Gjul. 2000. Females of the lekking great snipe do not prefer males with whiter tails. Anim. Behav. 59:273-280.

Sherman, P. W., and H. K. Reeve. 1999. Sexual selection and sensory exploitation. Science 283:1083a.

Swarup, H. 1958. Stages in the development of the stickleback Gasterosteus aculeatus (L.). J. Embryol. Exp. Morph. 6:373-383.

Takimoto, G., M. Higashi, and N. Yamamura. 2000. A deterministic genetic model for sympatric speciation by sexual selection. Evolution 54:1870-1881.

Taylor, E. B. 1998. Microsatellites isolated from the threespine stickleback Gasterosteus aculeatus. Mol. Ecol. 7:930-931.

Tsitrone, A., F. Rousset, and P. David. 2001. Heterosis, marker mutational processes and population inbreeding history. Genetics 159:1845-1859.

Turner, G. F., and M. T. Burrows. 1995. A model of sympatric speciation by sexual selection. Proc. R. Soc. Lond. B. Biol. Sci. 260:287-292.

Webberley, K. M., G. D. D. Hurst, J. Buszko, and M. E. N. Majerus. 2002. Lack of parasite-mediated sexual selection in a ladybird/ sexually transmitted disease system. Anim. Behav. 63:131-141.

Wegner, K. M., M. Kalbe, J. Kurtz, T. B. H. Reusch, and M. Milinski. 2003. Parasite selection for immunogenetic optimality. Science 301:1343.

Whoriskey, F. G., and G. J. FitzGerald. 1985a. Nest sites of the threespine stickleback: can site characters alone protect the nest against egg predators and are nest sites a limiting resource? Can. J. Zool. 63:1991-1994.

- 1985b. The effects of bird predation on an estuarine stickleback (Pisces: Gasterosteidae) community. Can. J. Zool. 63: 301-307.

Wiegmann, D. D., and J. R. Baylis. 1995. Male body size and paternal behaviour in smallmouth bass, Micropterus dolomieui (Pisces: Centrarchidae). Anim. Behav. 50:1543-1555.

Zhang, X. S., and W. G. Hill. 2003. Multivariate stabilizing selection and pleiotropy in the maintenance of quantitative genetic variation. Evolution 57:1761-1775.

Zuk, M., and K. A. McKean. 1996. Sex differences in parasite infections: patterns and processes. Int. J. Parasitol. 26: 1009-1023.

Corresponding Editor: L. Rowe 